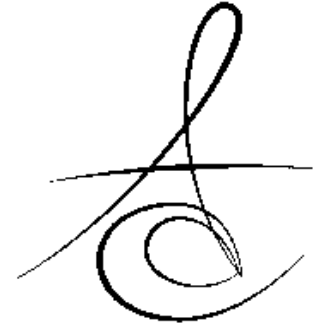

Makale Kodu/Article code: 1421

Makale Gönderilme tarihi: 26.11 .2013

Kabul Tarihi: 04.02.2014

\section{FIRÇALAMANIN VE BEYAZLATICILI DİŞ MACUNLARIN KOMPOZİTLERİN YÜZEY ÖZELLİKLERİNE ETKİSí}

\section{EFFECT OF BRUSHING AND WHITENING-TOOTHPASTE ON SURFACE PROPERTIES OF COMPOSITES}

\author{
Dr. Pınar Yılmaz ATALI* Prof. Dr. Mustafa ÖKsÜZ** \\ Prof. Dr. Faik Bülent TOPBASI*
}

\section{ÖZET}

Amaç: Bu çalışmanın amacı diş fırçası ve beyazlatıcı etkili dişmacunları ile fırçalama sonrası dört farklı kompozitin (hibrid, nanohibrid, nanofil ve siloran yapıda) yüzey pürüzlülüğü ve mikro sertliğinin in vitro incelenmesidir.

Gereç ve Yöntem: 80 adet örnek; Kontrol, Colgate Hareketli Beyazlatıc Diş fırçası (CWT), Opalescence Beyazlatıcı Diş Macunu (OWT) ve Beyond Pearl White Diş Macunu (BPW) olmak üzere 4 ana gruba ayrıldı $(n=20)$. Kontrol grubundaki örnekler 2 hafta boyunca distile suda bekletildi. Deney gruplarında ise; CWT ile sadece distile su ile fırçalama yapılırken; OWT ve de BPW dişmacunları ile ise günde 2 dakikadan 14 gün boyunca fırçalama yapıldı. 14 gün sonra yüzey pürüzlülüğü değeri (Sa) temassız üç boyutlu lazer profilometresi ile değerlendirilirken; yüzey sertlik değerleri Vickers testi ile ölçüldü. SEM incelemesi, x750 büyütmede yapıldı. İstatistiksel olarak Kruskal Wallis, post Hoc Dunn's multiple comparison, Mann Whitney $U$ testleri grupların karşılaştırılmasında kullanıldı. İstatistiksel değerlendirme $p<0,05$ anlamlılık düzeyinde yapıldı.

Bulgular: CWT ile fırçalama sonrası; hibrid ve nanofilin yüzey pürüzlülüğü anlamlı derecede artarken $(p<0,05)$; mikro sertlik değerleri etkilenmemiştir $(p \geq 0,05)$. Hibrid kompozit, BPW ile firçalama sonrası en pürüzlü yüzeye sahip olmuştur $(32,62 \pm 6,17)$. SEM incelemesinde fırçalama sonrasında hiçbir grupta yapısal değişikliliğe rastlanmamıştır.

Sonuç: Mikrohibrit tipte kompozitlerde organik yapının metakrilat ya da siloran olması sertlikteki ve pürüzlülükteki değişimler açısından anlamlı fark oluşturmamıştır. Nano kompozitlerin fırçalama ve beyazlatıcı etkili dişmacunları ile fırçalama sonrası yüzeylerindeki değişimler anlamlı farklılık oluşturmamıştır.

Anahtar Kelimeler: beyazlatıcılı diş macunu, fırçalama, kompozit dental rezin, mikro sertlik, yüzey pürüzlülüğü

\section{ABSTRACT}

Purpose: Purpose of this in vitro study is to compare the effect of brushing and two different whitening toothpaste brushing on surface roughness and microhardness of four different type of composites (hybrid' nanohybrid, nanofilled and silorane based composites). Material and Methods: 80 composite samples were prepared. Samples were classified into 4 main groups $(n=20)$ : Control,Colgate Motion Whitening Toothbrush (CWT),Opalescence Whitening Toothpaste (OWT) and Beyond Pearl White Toothpaste (BPW). Control group was stored in distilled water for 14 day, as baseline. CWT brushing were applied 2 minutes a day with distilled water or OWT or BPW for 14 days. After 14 days, surface roughness ( $\mathrm{Sa}$ ) was measured by noncontact 3D laser profilometer and surface hardness (VHN) were measured by Vickers tester. SEM Evaluation was done under $x 750$. Kruskal Wallis, post Hoc Dunn's multiple comparison, Mann Whitney U tests were used in the comparison of groups. Statistical significance level was established at $p<0.05$. Result: Although roughness's of the hybrid and nano filled composites were significantly increased $(p<0.05)$, there are no significant changes were measured in surface hardness of CWT brushed composite specimens $(p \geq 0.05)$. Hybrid composite showed the most roughness surface after brushing with BPW (32.62 \pm 6.17$)$. No structural changes were detected on SEM micrographs of all groups after brushing.

Conclusion: There is no significant differences between micro hardness of microhybrid composites which are neither methacrylate nor silorane based composites. Roughness and hardness of nano composites showed no significant difference after brushing with toothbrush and whitening toothpastes.

Keywords: whitening toothpaste, brushing, composite dental resin, micro hardness, surface roughness

*Marmara Üniversitesi Dişhekimliği Fakültesi Restoratif Diş Tedavisi Anabilim Dalı

**Marmara Üniversitesi Teknoloji Fakültesi, Metalurji ve Malzeme Mühendisliği Bölümü,

"Çalışmamız 20-23 Haziran 2012 tarihinde İguassu Brezilya' da düzenlenen IADR General Session Kongresi' nde poster sunumu olarak tebliğ edilmiştir.

"Çalışmamız Marmara Üniversitesi Bilimsel Araştırma Proje Komisyonun SAG-D-DRP-110412-0088 nolu projesi ile desteklenmiştir. 


\section{GİRİş}

Diş hekimi tarafından uygulanan beyazlatma ajanlarının yanı sıra, hastaların kendilerinin uygulayabileceği estetik uygulamaların başında beyazlatıcı etkili diş macunları gelir. Bu amaçla kullanılan diş macunlarının aşındırıcı partikül ya da özel enzimler içeren içerikleri ile ağızda bulunan diş dokusu ve restoratif materyallerin yüzeyinde değişiklikler meydana getirdikleri literatürde yer almaktadır. ${ }^{1-4}$

Beyaz dişlere olan talebin artması ve estetiğin ön plana çıkması ile beyazlatıcılı diş macunlarının da önemi artmıştır. Son yıllarda diş macunları; plağı, tartarı, çürüğü ve dentin hassasiyetini azaltmaya yönelik olanlar terapatik amaçlılar ve dişler üzerindeki lekeleri uzaklaştırarak dişlerin beyazlatmasını sağlayan kozmetik amaçlı diş macunları olarak iki kategoriye ayrılmışlardır. ${ }^{1,4-6}$ Beyazlatıcılı diş macunları, macunun temizlik etkinliğini arttırarak ya da dişlerin beyazlamasını sağlayarak etki gösterirler $\mathrm{Bu}$ amaçla hidrojen perokist (HP) ve karbamit perokist (KP), sodyum bikarbonat, silika ya da alüminyum oksit içerebilirler. ${ }^{6}$

Beyazlatıcı diş macunlarının büyük bir çoğunluğu dişleri beyazlatmaktan çok lekeleri kaldırma özelliği ile dişlerin rengini açmaktadır. Abrazivler dışında macun içindeki titanyum dioksit partikülleri de diş yüzeyindeki çukurcuklara dolarak dişin daha beyaz görünmesi ile illüzyon yaratır., ${ }^{3,6,7}$ Diş macununun aşındırma derecesi abraziv partiküllerin yapısının yanında partikülün şekline ve büyüklüğüne de bağlıdır. 6-8 Aynı zamanda hidrate silika ve kalsiyum karbonat gibi kimyasal olarak farklı yapıdaki abrazivlerin farklı temizleme ve aşındırma değerlerine sahip olduğu yapılan çalışmalarda gösterilmiştir .6,7,9

Fırça ile uygulanan kuvvet, fırçalama tekniği, fırçanın kıllarının sertliği ve yerleşimi fırçanın temizleme etkinliğini belirleyen faktörlerdir. Farklı açılarda ve uzunluklardaki fırça kıllarının geliştirilmesi ile günümüzde fırça tasarımla çok daha karmaşık hale gelmiştir. Diş macunu içindeki abraziv partiküller ile fırça kıllarının teması ile diş yüzeyindeki plak ve lekeleri uzaklaştırma mekanizması araştırımaktadır. ${ }^{10}$ Manuel diş fırçası kullanılarak diş fırçalandığında 140 gr -720 gr arasında yük uygulandığı (ortalama değer olarak 330 gr) tespit edilmiştir. ${ }^{11}$ Elektrikli diş fırçalarının performansını, uygulanan yük ve diş macunu kullanımı etkilemektedir. Fazla yük uygulaması fırçalama etkinliğini azaltmaktadır. ${ }^{12}$
Rezin bazlı kompozitlerde fırçalamanın yüzeyi aşındırdığı bildirilmiştir. Fırçalama sırasında yumuşak polimer matriks aşınarak geriye inorganik yapıyı bırakmaktadır. Fırça kılları polisajda kullanılan lastik frezler ya da diskler gibi doldurucuları aşındırıp düzleştiremediğinden, yüzey pürüzlü kalmaktadır. ${ }^{13}$

Bolen ve ark. ${ }^{14} 70$ farklı kompozit materyalinin fırçalama sonrası yüzey pürüzlülüklerindeki değişimlerini inceledikleri çalışmalarında; test ettikleri materyallerin $\% 70^{\prime}$ inden fazlasında yüzey pürüzlülüğü değerinin $0.2 \mu \mathrm{m}^{\prime}$ dan fazla ve $\% 40$ 'nın da $0.64 \mu \mathrm{m}^{\prime}$ dan fazla olduğunu yayınlamışlardır. Ancak çalışmalarında fırçalama öncesi pürüzlülük değerlerini ölçmedikleri için pürüzlülükte artış ya da azalış olup olmadığına dair bir değerlendirmeyi kapsamamaktadır.

Rezin kompozitlerin mekanik ve fiziksel özelliklerini arttırmak amacıyla inorganik ve organik yapı modifiye edilerek yeni kompozitler geliştirilmiştir. Nano partiküllü kompozit materyallerin organik yapısı da, diğer geleneksel ve hibrit kompozitler gibi benzer polimer yapılardan meydana geldiği ve estetik özelliklerinin yanında mekanik özelliklerinin de hibrit kompozitlerle eşit veya daha üstün olduğu bildirilmiştir. ${ }^{15-19}$ Kompozit rezinlerdeki yenilikler inorganik yapının yanında organik yapıyı da içermektedir. Rezin kompozitin matriks yapısını oluşturan metakrilatların yerine "siloran" adı verilen bu yeni tipteki organik yapılar oluşturmaktadır. Siloran siloksanlar ve oksiranların kombinasyonudur. Siloksan alt yapısı oldukça hidrofobik olup, su absorbsiyonunu sınırlaması önem kazanmaktadır. ${ }^{20}$ Yapılan çalışmalar kompozit yapının mekanik ve fiziksel özelliklerinin yüksek olup su adsorbsiyonundan etkilenmediğini göstermektedir. Polimerizasyon büzülmesinin en düşük seviyede olduğu ve bunun yanı sıra su emme kapasitesinin düşük olduğu öne sürülen bu yeni materyalin beyazlatıcılı diş macunlarına karşı mekanik özelliklerinin nasıl değiştiğine dair literatür bilgisi yeterli değildir. Yapılan çalışmalar polimerizasyon büzülmesi, su emme kapasitesine bağlı meydana gelen mekanik özelliklerdeki gelişmeler ve polimerizasyon büzülmesine bağlı dişteki stres dağıımı ile ilgili çalışmalardır. ${ }^{21-25}$

Çalışmamızda 4 farklı dental rezin kompozite diş fırçası ve 2 farklı beyazlatıcı diş macunu ile 14 gün boyunca fırçalanması sonucu kompozit yüzeylerinin, yüzey pürüzlülüğü ve mikro sertlik değişimlerinin in vitro olarak incelenmesi amaçlanmıştır. 


\section{GEREÇ VE YÖNTEM}

$\mathrm{Bu}$ çalışmada incelenen 4 farklı kompozit materyali Tablo 1'de, diş fırçası ve 2 farklı tipte beyazlatıcılı diş macunu ise Tablo 2'de gösterilmektedir.

Tablo 1. Çalışmada kullanılan kompozit rezinlerin üretici firma bilgilerine göre içerikleri

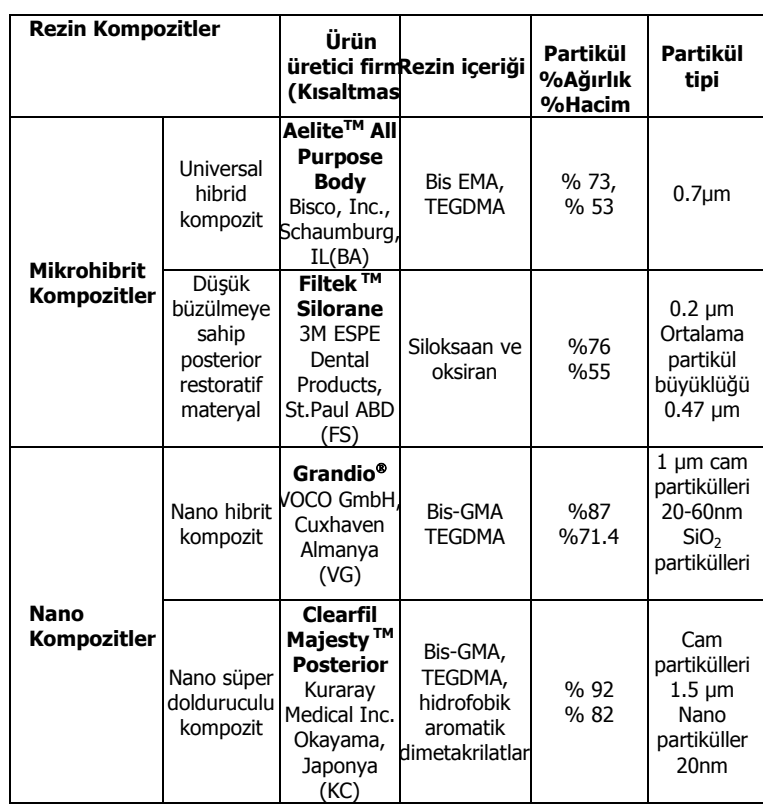

\section{Örneklerin Hazırlanması}

Örneklerin hazırlanmasında $10 \times 10 \mathrm{~mm}$ boyutlarında ve $2 \mathrm{~mm}$ kalınlığında kare şeklinde teflon kalıplardan yararlanıldı. Her bir kompozit materyalinin A3 rengi kullanılarak 20'şer örnekten toplam 80 adet örnek hazırlandı. Restoratif materyaller kalıplara teflon spatül ile yerleştirildikten sonra üzerine şeffaf bantlar uygulandı ve fazla materyalin uzaklaştırıması için her iki tarafından siman camı ile bastırıldı. Örnekler şeffaf bant ve siman camı altında Freelight 2 (Freelight 2, 3M ESPE, Seefeld, Almanya) cihazı ile 40 sn polimerize edildi. Örnekler düşük turda su soğutmalı Sof-Lex diskler (3M Dental Products, St.Paul, ABD) yardımıyla orta, ince ve süper ince diskler kullanılarak cilalandı. Cilalanan örnekler içinde distile su bulunan ultrasonik temizleyicide yüzeydeki artıkların uzaklaştırılması amacıyla 2 dakika temizlendi Testlere başlamadan önce tüm örnekler oda sıcaklığında 24 saat distile suda bekletildi
Tablo 2. Çalışmamızda kullanılan beyazlatıcı diş macunlarının içerikleri

\begin{tabular}{|c|c|c|}
\hline Materyaller & $\begin{array}{l}\text { Ürün ismi, } \\
\text { üretici firma } \\
\text { (Kısaltması) }\end{array}$ & \% Aktif İçeriği \\
\hline \multirow[b]{2}{*}{$\begin{array}{c}\text { Beyazlatıcı } \\
\text { Diş } \\
\text { Macunları }\end{array}$} & $\begin{array}{c}\text { Opalescence } \\
\text { Whitening } \\
\text { Toothpaste } \\
\text { Ultradent } \\
\text { Products Inc. } \\
\text { South Jordan, UT } \\
\text { (OWT) }\end{array}$ & $\begin{array}{l}\text { sodyum florid \% } 0.25 \text { (1100 ppm } \\
\text { F), gliserin, distile su, silika, } \\
\text { sorbitol, ksilitol, doğal tat } \\
\text { (aroma), poloksamer, SLS, } \\
\text { xanthan gum, karbomer, sodyum } \\
\text { benzoat, FD\&C Blue No. } 1 \text { (CI } \\
\text { 42090), FD\&C Yellow No. 5(CI } \\
\text { 19140) ve Splenda } \circledR\end{array}$ \\
\hline & $\begin{array}{l}\text { Beyond }^{\mathrm{TM}} \text { Pearl } \\
\text { White } \\
\text { Toothpaste } \\
\text { BEYOND } \\
\text { Technology Corp. } \\
\text { Nanchang } \\
\text { Nanchang, } \\
\text { Jiangxi, Çin } \\
\text { (BPW) }\end{array}$ & 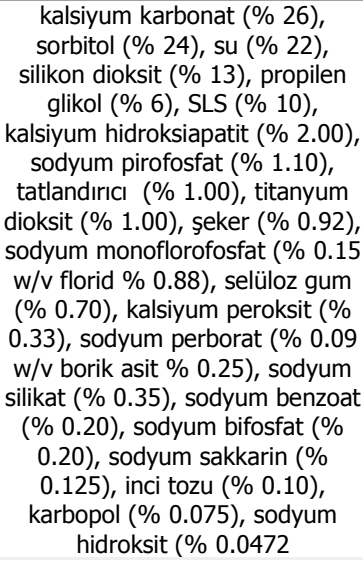 \\
\hline $\begin{array}{l}\text { Beyazlatıcı } \\
\text { Diş Fırçası }\end{array}$ & $\begin{array}{l}\text { Colgate }^{\circledR} \\
\text { Motion }^{\text {TM }} \\
\text { Whitening } \\
\text { Toothbrush } \\
\text { (Colgate - } \\
\text { Palmolive } \\
\text { Company New } \\
\text { york, NY 10022) } \\
\text { (CWT) }\end{array}$ & $\begin{array}{l}\text { Diş Fırçası çift hareketli fırça } \\
\text { başına sahiptir. Küçük başlık diş } \\
\text { aralarını ve diş-diş eti birleşimini } \\
\text { derinlemesine temizleyen bir uç } \\
\text { görevi görürken, büyük başlık } \\
\text { plak tabakasını temizleyerek diş } \\
\text { yüzeyini parlatır. Fırça üzerindeki } \\
\text { yumuşak siliciler lekeleri } \\
\text { gidermeye yardımcı olur. }\end{array}$ \\
\hline
\end{tabular}

\section{Grupların Oluşturulması}

Hazırlanan 80 adet örnek $n=20$ olarak 4 ana gruba ayrıldı:

Grup 1: Kontrol Grubu

Grup 2: Colgate ${ }^{\circledR}$ Motion $^{\mathrm{TM}}$ Whitening (Colgate -Palmolive Company New york, NY 10022) Diş fırçası Grubu (CWT)

Grup 3: Opalescence ${ }^{\circledR}$ Whitening Toothpaste (Ultradent Products Inc. South Jordan, UT.) Diş Macunu Grubu (OWT)

Grup 4: Beyond ${ }^{\mathrm{TM}}$ Pearl White Toothpaste BEYOND Technology Corp. Nanchang Nanchang, Jiangxi, Çin) Diş macunu Grubu (BPW).

Her bir grup içinde de 4 farklı tip kompozitin oluşturduğu $n=5$ olmak üzere 4 alt grup oluşturuldu: Aelite $^{\mathrm{TM}}$ All Purpose Body (Bisco, Inc., Schaumburg, IL) grubu (BA); 
Filtek $^{\mathrm{TM}}$ Silorane (3M ESPE Dental Products, St.Paul ABD) grubu (FS);

Grandio $^{\circledR}$ (VOCO GmbH, Cuxhaven Almanya) grubu (VG);

Clearfil Majesty ${ }^{\mathrm{TM}}$ Posterior (Kuraray Medical Inc. Okayama, Japonya) grubu (KC).

\section{Yüzey Pürüzlüllüğünün ölçüllmesi}

Hassas ve detaylı yüzey profillendirme ve ölçüm sistemi olan UNISCAN OSP 100A (Uniscan OSP 100A, AG Electro Optics UK) lazer sensörler yardımıyla ölçüm yapıldı. Kompozit rezin örneklerinin yüzeylerinden $6 \times 6$ $\mathrm{mm}^{2}$ ' lik alanlar $20 \mu \mathrm{m}^{\prime}$ luk aralık ile $500 \mathrm{~Hz}$ (Hertz) ile $10 \mathrm{~mm} / \mathrm{sn}$ hızla tarandı. Bir örneğin yüzey taraması 5 dakika sürdü. Her bir örnekten 3 tarama yapılarak ortalama değeri alındı. Ölçümlerde Sa değerleri istatiksel değerlendirmeye alındı.

$$
\mathbf{S}_{\mathbf{a}}=\frac{1}{M N} \sum_{j=1}^{N} \sum_{\mathrm{i}=1}^{M}\left|\eta\left(\mathrm{x}_{\mathrm{i}}, \mathrm{y}_{\mathrm{i}}\right)\right|
$$

M her bir çizgideki numune sayısı

N çizgi sayısı,

i çizginin belli bir bölümündeki özel indeksi,

$\mathbf{j}$ çizginin kendine ait indeksi,

$\mathbf{n}(\mathbf{x i}, \mathbf{y j})$ yj çizgisindeki en yüksek xi noktası ile yüzeydeki tüm ortalama noktalar arasındaki farkı göstermektedir.

Grupların oluşturulmasından sonra ilk ölçümler, 24 saat oda sıcaklığında distile suda bekleyen kontrol grubuna yapıldı. Her ölçüm, hata payının azaltılması amacıyla, 3'er kez yapıldı. İlk ölçümlerin sonrasında örnekler distile suda bekletildi. Diş fırçası, Beyazlatıcı Diş macunu gruplarında Opalescence Whitening Toothpaste (OWT) ve Beyond Pearl White (BPW) diş macunu ile $100 \mathrm{gr}$ yük altında (Şekil 1) firçalama sonrası 14 gün sonunda yüzey ölçümleri yapıldı. Diş fırçası grubunda yapılan firçalamalarda sadece distile su kullanılırken, diş macunu gruplarında ise firçalama diş macunları seyreltimeden, numunenin tüm yüzeyini kaplayacak miktarda kullanıldı. Optik profilometre ile taranan görüntüler IsoPlot programında üç boyutlu grafik olarak kaydedildi.

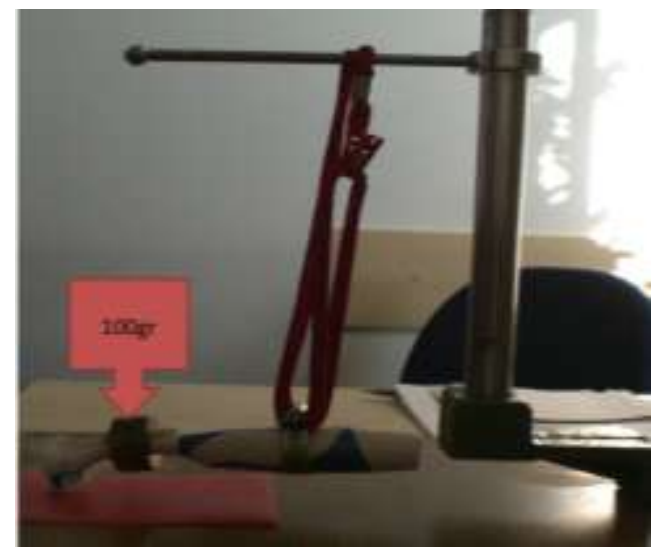

Şekil 1. Diş fırçası düzeneği

\section{Mikrosertliğin Ölçülımesi}

BMS 200-RBOV Rockwell, Brinell \&Vickers sertlik ölçme cihazı (Bulut Makina Sanayi Limited Şirketi, İkitelli, İstanbul, Türkiye) kullanılarak örneklerin mikro sertlik değerleri hesaplandı. Çalışmamızda her bir örneğin yüzey sertlik değeri $100 \mathrm{gr}^{\prime}$ lık yük ve $20 \mathrm{sn}$ bekleme süresi kullanılan yüzey sertlik cihazı ile alındı ve başlangıç ölçümleri olarak kaydedildi. Her bir örnekten birbirlerine ya da kenarlarına $1 \mathrm{~mm}$ 'den daha yakın olmayacak şeklide 3 ölçüm alındı ve bu ölçümlerin ortalaması her bir örnek için tek bir değer olarak kabul edildi. Deney grubu örneklerinin (diş fırçası ve iki farkı beyazlatıııı diş macunu grupları) sertlik değerleri de 14 gün sonra ölçüldü. Örneklerin mikrosertlik değerleri $\mathrm{H}=1.854 \mathrm{P} / \mathrm{d}^{2}$ formülü ile hesaplandı. Bu formülde $p$ yükü, $d$ ise izin diagonal uzunluğunu belirtmektedir.

\section{SEM (Scanning Electron Microscope)}

\section{Analizi}

Örnekler $20 \mathrm{kV}$ düşük vakum altında JEOL Scanning Electron Microscope (JSM,Japonya) 5410 ile x750 büyütmede yapıldı. 16 gruptan en yüksek pürüzlülük değerine sahip birer örneğin SEM incelemesi yapıldı.

\section{Ístatistiksel Analiz}

Bu çalışmada istatistiksel analizler NCSS 2007 paket programı ile yapılmışır. Verilerin değerlendirilmesinde tanımlayıcı istatistiksel metotların (ortalama, standart sapma) yanı sıra gruplar arası karşılaştırmalarda Kruskal Wallis testi alt grup karşılaştırmalarında Dunn's çoklu karşılaştırma testi, ikili grupların karşılaş- 
tırmasında Mann-Whitney-U testi kullanılmıştır. Sonuçlar, anlamlılık $p<0,05$ düzeyinde değerlendirilmiştir.

\section{BULGULAR}

\section{Mikro Sertlik Bulguları}

Distile suda bekletilen kontrol gruplarında; mikrohibrit yapıdaki kompozitlerin (BA ve FS); organik yapının metakrilat ya da siloran bazlı olması farketmeksizin başlangıç ve 2.hafta sertlik değerleri arasında istatistiksel olarak anlamlı farklılık gözlenmezken; nano kompozitlerin ( $K C$ ve VG) 2. hafta sertlik değerleri başlangıç değerlerinden istatistiksel olarak anlamlı derecede yüksek bulunmuştur $(p=0,008)$ (Tablo 3$)$.

Tablo 3. Kontrol grubundaki kompozitlerin başlangıç ve iki hafta sonraki mikro sertlik değerleri (VHN) ve standart sapmaları (sd)

\begin{tabular}{lllll}
\hline \hline $\begin{array}{l}\text { Sertlik } \\
\text { Kontrol }\end{array}$ & $\begin{array}{l}\text { Başlangıç } \\
\text { VHN } \pm \text { sd }\end{array}$ & $\begin{array}{l}\text { 2.Hafta } \\
\text { VHN } \pm \text { sd }\end{array}$ & Z & p \\
\hline BA & $61,09 \pm 6,07$ & $59,59 \pm 4$ & 9 & 0.548 \\
\hline VG & $77,79 \pm 4,07$ & $99,7 \pm 1,53$ & 0 & $\mathbf{0 . 0 0 8 *}$ \\
\hline KC & $118,53 \pm 8,78$ & $133,73 \pm 4,06$ & 0 & $\mathbf{0 . 0 0 8 *}$ \\
\hline FS & $59,15 \pm 3,38$ & $62,89 \pm 3,57$ & 5 & 0.151 \\
\hline \hline
\end{tabular}

BA: Bisco Aelite $\quad \boldsymbol{K}$ : : Kuraray Clearfil Majesty

VG: Voco Grandio FS: Filtek Silorane

CWT ile fırçalama sonrasında BA, KC, VG ve FS gruplarının sertlik ortalamaları arasında istatistiksel olarak anlamlı farklılık gözlenmiştir $(p=0.0005)$. KC grubunun sertlik ortalamaları BA ve FS gruplarından istatistiksel olarak anlamlı derecede yüksek bulunmuş $(P<0.05, P<0.001)$, diğer gruplar arasında istatistiksel olarak anlamlı farklılık gözlenmemiştir ( $p$ >0.05). (Tablo 4)

BPW ile fırçalama sonrasında BA, KC, VG ve FS gruplarının sertlik ortalamaları arasında istatistiksel olarak anlamlı farklılık gözlenmiştir $(p=0.0005)$. KC grubunun sertlik ortalamaları BA ve FS gruplarından istatistiksel olarak anlamlı derecede yüksek bulunmuş $(P<0.05)$, VG grubunun sertlik ortalamaları FS gruplarından istatistiksel olarak anlamlı derecede yüksek bulunmuş $(P<0.001)$, diğer gruplar arasında istatistiksel olarak anlamlı farklılık gözlenmemiştir ( $p$ >0.05), (Tablo 4).

OWT firçalama sonunda BA, KC, VG ve FS gruplarının sertlik ortalamaları arasında istatistiksel olarak anlamlı farklılık gözlenmiştir $(p=0.0005)$ KC grubunun sertlik ortalamaları BA ve FS gruplarından istatistiksel olarak anlamlı derecede yüksek bulunmuş $(P<0.05)$, VG grubunun sertlik ortalamaları FS grupla rından istatistiksel olarak anlamlı derecede yüksek bulunmuş $(P<0.05)$, diğer gruplar arasında istatistiksel olarak anlamlı farklılık gözlenmemiştir ( $p$ >0.05), (Tablo 4).

BA grubunun OWT ile fırçalama sonrası sertlik değerleri, BPW ile fırçalama sonrası sertlik değerlerinden istatistiksel olarak anlamlı derecede yüksek bulunurken $(p=0,008)$; Nano grupları olan KC ve VG gruplarının OWT ile fırçalama sonrası sertlik değerleri, BPW ile fırçalama sonrası sertlik değerlerinden istatistiksel olarak anlamlı derecede düşük bulunmuştur $(p=0,008)$. FS grubunda ise anlamlı farklılık gözlenmemiştir $(p=0,095)$. (Tablo 5)

Tablo 4 Kontrol grubu, diş fırçası ve iki farklı beyazlatıcı diş macunu ile firçalama sonrası Vickers sertlik değerlerinin (VHN) ortalaması ve standart sapmaları (sd).

\begin{tabular}{lllllll}
\hline \hline (Sertlik) & BA & KC & VG & FS & & \\
\hline $\begin{array}{l}\text { Kontrol } \\
\text { 2.Hafta }\end{array}$ & $59,59 \pm 4$ & $133,73 \pm 4,06$ & $99,7 \pm 1,53$ & $62,89 \pm 3,57$ & 16,42 & $\mathbf{0 . 0 0 0 9 *}$ \\
\hline & & & & & & \\
BPW & $69,29 \pm 5,09$ & $126,46 \pm 1,85$ & $69,1 \pm 2,48$ & $55,58 \pm 1,37$ & 17,83 & $\mathbf{0 . 0 0 0 5 *}$ \\
\hline & & & & & & \\
OWT & $81,19 \pm 2,03$ & $116,45 \pm 1,98$ & $99,57 \pm 6,52$ & $58,97 \pm 2,66$ & 17,86 & $\mathbf{0 . 0 0 0 5 *}$ \\
\hline & & & & & & \\
CWT & $64,06 \pm 4,87$ & $119,01 \pm 3,41$ & $99,57 \pm 6,52$ & $55,68 \pm 1,32$ & 17,58 & $\mathbf{0 . 0 0 0 5 *}$ \\
\hline
\end{tabular}

BA: Bisco Aelite $\quad$ KC: Kuraray Clearfil Majesty

VG: Voco Grandio FS: Filtek Silorane

BPW: Beyond Pearl White Dis Macunu

OWT: Opalescence Whitening Toothpaste Diş Macunu

CWT: Colgate Whitening Motion Diş FIrçası

Tablo 5. Beyond Pearl White Diş Macunu (BPW) ve Opalescence Whitening Toothpaste Diş Macunu (OWT) ile fırçalama sonrası; iki beyazlatıcı diş macunun Vickers mikrosertlik değerlerinin (VHN) ve standart sapmaları (sd) kıyaslanması

\begin{tabular}{llllll}
\hline \hline \multirow{3}{*}{ Sertlik } & & BPW & OWT & & \\
\hline & & VHN \pm sd & VHN \pm sd & MW & p \\
\cline { 2 - 7 } & KC & $69,29 \pm 5,09$ & $81,19 \pm 2,03$ & 0 & $\mathbf{0 . 0 0 8 *}$ \\
\cline { 2 - 7 } & VG & $126,46 \pm 1,85$ & $116,45 \pm 1,98$ & 0 & $\mathbf{0 . 0 0 8 *}$ \\
\cline { 2 - 7 } $\begin{array}{l}\text { Diş } \\
\text { Macunu }\end{array}$ & FS & $51,28 \pm 2,13$ & $69,1 \pm 2,48$ & 0 & $\mathbf{0 . 0 0 8 *}$ \\
\hline
\end{tabular}

BA: Bisco Aelite $\quad$ KC: Kuraray Clearfil Majesty

VG: Voco Grandio FS: Filtek Silorane

BPW: Beyond Pearl White Diş Macunu

oWT: Opalescence Whitening Toothpaste Diş Macunu 


\section{Yüzey Pürüzlülüğü Bulguları}

16 grubun en pürüzlü değere sahip örneklerinin 3 boyutlu yüzey görüntüleri Şekil 2'de görülmektedir.

UNISCAN OSP 100A (Uniscan OSP 100A, AG Electro Optics UK) lazer sensörler yardımıyla yapılan ölçümlere göre; kontrol grubu 2. hafta BA, KC, VG, FS gruplarının pürüzlülük ortalamaları arasında istatistiksel olarak anlamlı farklılık gözlenmiştir $(p=0.0018)$. FS grubunun pürüzlülük ortalamaları $B A$ ve $K C$ gruplarından istatistiksel olarak anlamlı derecede yüksek bulunmuş $(P<0.01, P<0.05)$, diğer gruplar arasında istatistiksel olarak anlamlı farkllık gözlenmemiştir $(P>0.05)$. En pürüzlü yüzeye $F S$ kompozit sahiptir (Tablo 6), (Şekil 2).

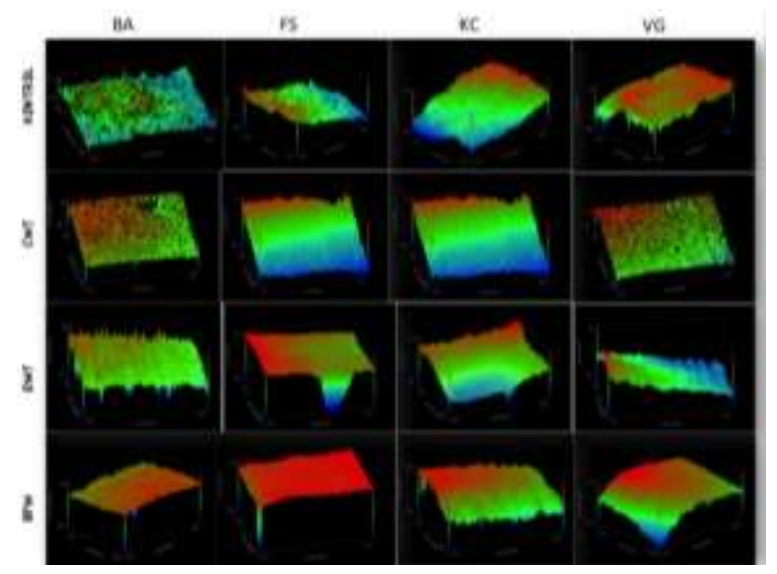

Şekil 2. BA, FS, KC ve VG kompozit örneklerinin kontrol, CWT, OWT ve BPW ile fırçalama sonrası 3 boyutlu yüzey görüntüleri (BA: Bisco Aelite KC: Kuraray Clearfil Majesty VG: Voco Grandio FS: Filtek Silorane BPW: Beyond Pearl White Diş Macunu OWT: Opalescence Whitening Toothpaste Diş Macunu CWT: Colgate Whitening Motion Diş Fırçası)
CWT diş fırçası ile fırçalama sonrası BA ve KC kompozitin pürüzlülük değeri anlamlı olarak artarken FS kompozitin azalmıştır (Tablo 6).

BPW ile firçalanan BA grubunun pürüzlülüğünde istatistiksel olarak artma olmuştur ve $B A$ en yüksek pürüzlülük değerine ulaşmıştır $(32,62 \pm 6,17)$. OWT ile firçalanan gruplarda ise; KC ve VG grubunun pürüzlülük değeri anlamlı olarak değişmemiş̧ir $(p=0,421)$. Beyazlatıcı diş macunu ile fırçalama sonrası en az etkilenen kompozit grubu VG olmuştur (Tablo 6).

Mikrohibrit gruplarında; BA grubunun OWT ile fırçalama sonrası pürüzlülük değerleri BPW ile fırçalama sonrası pürüzlülük değerlerinden istatistiksel olarak anlamlı derecede düşük bulunurken; $(p=0,008)$; FS grubunda anlamı derecede yüksek bulunmuştur. $(p=0.032)$. Nano gruplarda ise; KC grubunun OWT sonrası pürüzlülük değerleri BPW değerlerinden istatistiksel olarak anlamlı derecede yüksek bulunurken; $(p=0,008)$. VG grubunun OWT ve BPW ile fırçalama sonrası pürüzlülük değerleri arasında istatistiksel olarak anlamlı farklılık gözlenmemiştir $(p=0.421)$ (Tablo 7), (Şekil 2).

Tablo 7. BPW Beyond Pearl White Dis Macunu (BPW) ve Opalescence Whitening Toothpaste (OWT) ile firçalama sonrası; iki beyazlatıcı diş macunun yüzey pürüzlülüğü ortalama değerlerinin (Sa) kıyaslanması

\begin{tabular}{llllll}
\hline \hline \multirow{2}{*}{ Pürüzlülük } & & \multicolumn{3}{l}{ BPW } & OWT \\
& & Sa \pm sd & Sa \pm sd & MW & p \\
\hline & BA & $32,62 \pm 6,17$ & $14,49 \pm 2,8$ & 0 & $\mathbf{0 , 0 0 8 *}$ \\
\cline { 2 - 6 } & KC & $13,75 \pm 3,95$ & $24,75 \pm 3,87$ & 0 & $\mathbf{0 . 0 0 8 *}$ \\
\cline { 2 - 6 } & VG & $20,79 \pm 7,17$ & $16,32 \pm 2,11$ & 8 & 0.421 \\
\cline { 2 - 6 } $\begin{array}{l}\text { Diş } \\
\text { Macunu }\end{array}$ & FS & $23,49 \pm 2,39$ & $32,06 \pm 5,89$ & 2 & $\mathbf{0 . 0 3 2 *}$ \\
\hline
\end{tabular}

BA: Bisco Aelite KC: Kuraray Clearfil Majesty

VG: Voco Grandio FS: Filtek Silorane

BPW: Beyond Pearl White Diş Macunu

OWT: Opalescence Whitening Toothpaste DişMacunu

Tablo 6. Kontrol, diş fırçası (Colgate Whitening Motion) ve diş macunu gruplarının (Beyond Pearl White ve Opalescence Whitening Toothpaste) yüzey pürüzlülüğü ortalama değerleri (Sa) ve standart sapmaları (sd)

\begin{tabular}{|c|c|c|c|c|c|c|}
\hline (Pürüzlülük) & $\begin{array}{l}\text { BA } \\
\text { Sa } \pm \text { sd } \\
\end{array}$ & $\begin{array}{l}\mathbf{K C} \\
\mathrm{Sa} \pm \mathrm{sd} \\
\end{array}$ & $\begin{array}{l}\mathbf{V G} \\
\mathrm{Sa} \pm \mathrm{sd} \\
\end{array}$ & $\begin{array}{l}\mathbf{F S} \\
\mathrm{Sa} \pm \mathrm{sd}\end{array}$ & KW & $\mathbf{p}$ \\
\hline Kontrol & $16,81 \pm 1,17$ & $13,74 \pm 5,11$ & $20,58 \pm 3,11$ & $35 \pm 1,78$ & 14,98 & $0.0018 *$ \\
\hline BPW & $32,62 \pm 6,17$ & $13,75 \pm 3,95$ & $20,79 \pm 7,17$ & $23,49 \pm 2,39$ & 11,5 & 0.009* \\
\hline OWT & $14,49 \pm 2,8$ & $24,75 \pm 3,87$ & $22,38 \pm 10,22$ & $32,06 \pm 5,89$ & 15,8 & $0.0012 *$ \\
\hline CWT & $34,69 \pm 7,13$ & $31,29 \pm 8,22$ & $16,32 \pm 2,11$ & $23,67 \pm 1,64$ & 7,29 & 0.063 \\
\hline
\end{tabular}

BA: Bisco Aelite KC: Kuraray Clearfil Majesty VG: Voco Grandio FS: Filtek Silorane BPW: Beyond Pearl White Diş Macunu OWT: Opalescence Whitening Toothpaste Diş Macunu CWT: Colgate Whitening Motion Diş Firçası 


\section{SEM}

Diş fırçası ve beyazlatıcılı diş macunları ile fırçalama yapılan kompozit yüzeylerinden $x 750$ büyütmede alınan SEM görüntüleri incelendiğinde; kompozit yüzeylerinde herhangi bir çatlak, kırık, inorganik partiküllerin kopmasına rastlanılmamıştır. Her bir gruptan en pürüzlü yüzeye sahip birer örneğin SEM görüntüleri Şekil 3' te görülmektedir.

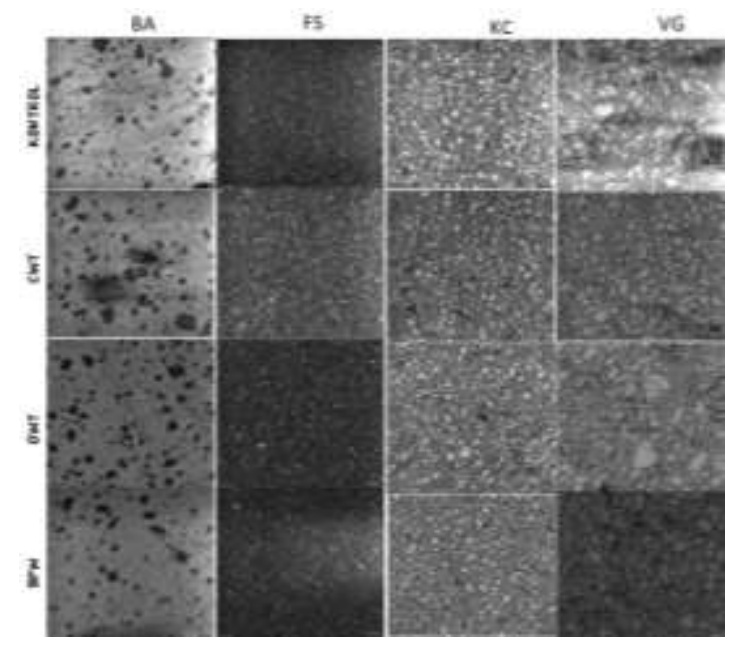

Şekil 3. BA, FS, KC ve VG kompozit örneklerinin kontrol, CWT, OWT ve BPW ile firçalama sonrası SEM Görüntüleri, x750 (BA: Bisco Aelite KC: Kuraray Clearfil Majesty VG: Voco Grandio FS: Filtek Silorane BPW: Beyond Pearl White Dis Macunu OWT: Opalescence Whitening Toothpaste Diş Macunu CWT: Colgate Whitening Motion Diş Fırçası)

\section{TARTIŞMA}

Hem rezin matriks hem de doldurucu partikül tipi veya içeriği diş fırçalama ve doldurucu partiküllerin yer değiştirmesi sonrasında yüzeyin durumunu etkilemektedir. Test aygıtının tipi, yükler, vuruş sayısı, diş fırçasının tipi, diş macununun tipi gibi çok fazla sayıda parametrenin diş fırça ve macun abrazyonu çalışılırken her grup için standardize edilmesi gerekmektedir. ${ }^{26} \mathrm{Bu}$ çalışmada iki farklı beyazlatıcı diş macunu aynı diş fırçası ile (Colgate ${ }^{\circledR}$ Motion $^{\mathrm{TM}}$ Whitening Toothbrush Colgate Palmolive Company, İstanbul, Tütkiye) test edilen her örneğe $100 \mathrm{gr}^{\prime}$ lık yük altında 5 dakika boyunca uygulanmıştır.

Pamir ve ark. aşındırıcılık dereceleri farklı beyazlatıcı diş macunlarının kompozit rezinlerin yüzey pürüzlülüğü ve mikro sertliğe etkilerini inceledikleri çalışmalarında her bir materyal örneği 10 dakikalık fırçalama süresi, ağızda 28 diş olduğu varsayılarak, 2 dakika boyunca günde 2 kez dişlerini fırçalayan bir bireyin, yaklaşık 1 aylık diş fırçalama süresine eşdeğer olarak hesaplamışlardır. ${ }^{27}$ Her bir materyal örneği için 5 dakikalık fırçalama süresi, ağızda 28 diş olduğu varsayılarak, 2 dakika boyunca günde 2 kez dişlerini fırçalayan bir bireyin, yaklaşık 14 günlük diş fırçalama süresine eş değer olarak hesaplandı.

Yüzey pürüzlülüğü için; mekanik bir sensör yardımı ile tarayan mekanik profilometrelerin kullanıldığı çok sayıda çalışma literatürde mevcuttur. Bu cihazların en büyük dezavantajı, sensör ucun tüm düzensizliklerin içine penetre olamaması ve numuneye zarar vermesidir. ${ }^{28-30}$ Optik profiolmetrenin iki önemli avantajı mevcuttur; birincisi SEM ile sağlayamayacağımı ölçümler verir, ikincisi de mekanik profiolmetrenin tarayıcı ucunun algılayamayacağı küçüklükte düzensizlikleri, optik profilometrenin sensör uçundan çıkan optik ışık demeti daha hassas olarak algılar. ${ }^{28-31}$

Joniot ve ark. Dört faklı estetik restoratif materyalin mekanik ve optik profilometre ile yüzey pürüzlülüklerini değerlendirdikleri çalışmalarında; mekanik profilometrenin daha çok ciladan kaynaklı pürüzlülüğü ölçtüğünü optik profilometrenin ise materyalin kendi yapısından kaynaklanan pürüzlülüğü ölçme eğiliminde olduğunu bildirmişlerdir. ${ }^{28}$ Yüzey pürüzlülüğü ölçmede optik lazer profilometre kullanılarak alan taraması yapıldığında, pürüzlülük değeri olan Sa'nın, her cihazın kendi hesaplama denklemine göre değerlendirilmesi gerektiğini bildirilmiştir. ${ }^{31-33}$ Çalışmamızda yüzey pürüzlülüğü ölçmede mekanik profilometre yerine optik lazer profilometre kullanılmıştır. Lazer ile taramada alan taraması yapılarak yüzeydeki tüm düzensizlikler hesaplanmıştır. SEM görüntüleri alarak kalitatif profilometre görüntülerimizi kantitatif olarak da desteklenmiştir. Pürüzlülük değeri olarak OSP cihazının hesapladığı Sa değerleri kullanılmıştır.

Diş fırçalama sırasında diş macunu tükürük ile hızlı bir şekilde seyreltilmektedir, in vitro deneylerde ise diş macunu distile su ile seyreltilmektedir. Ancak; spesifik proteinleri ve iyonları içeren spesifik yapıdaki tükürük, diş fırçalama sırasında pürüzlülüğü etkilemektedir. $^{11,33}$ ISO standartlarına göre fırçalama ile ilgili testlerde 0.5 ile $2.5 \mathrm{~N}$ arasında yük uygulaması gerektiği belirtilmiştir ancak; bu çalışmalar materyallerindeki aşınmayı belirlemek için uygulanan çalışmalardır. Diş fırçası ve diş macunlarının kompozit mater- 
yalini aşındırmasında; kullanılan abrazyon test cihazı, kompozit rezinin kendisi, diş macunu içeriği ve fırçanın tipinin etkili olduğu bildirilmiştir. ${ }^{33}$

Heintze ve ark. ${ }^{33} 16$ kompozit rezin, 4 seramik ve 1 amalgam materyali olmak üzere toplam 21 farklı dental materyalin fırçalama sonrası yüzey pürüzlülüklerini değerlendirdikleri çalışmalarında; genel olarak hibrit kompozitlerin mikrofil kompozitlere göre yüzey değişimlerine daha yatkın oldukları; bunun yanında seramik ve amalgam materyallerinde yüzey pürüzlülüğünde bir artışa rastlamadıklarını bildirmişlerdir.

Heintze ve ark., ${ }^{11}$ 100/250/350gr olmak üzere 3 farklı yükü 1 saaten 10 saate kadar fırçalamayı simüle eden test cihazında mikrofil, mikro hibrid, hibrid, makro hibrid ve seramik materyaller üzerine fırçalama testleri yaptıkları çalışmalarında; mikrofil kompozitler haricinde kompozitlerin birçoğunda artan fırçalama yükü ve zamanı karşısında yüzey pürüzlülüklerinin arttığını belirtmişlerdir. Yine aynı çalışmada kompozit materyallerde yıpranma potansiyeli görebilmek için için 10 saat fırçalama süresine gerek olduğu, ancak bu sürenin hibrid kompozitler için 5 saat olarak tespit edildiği bildirilmiştir.

Silika ve kalsiyum karbonat içeren beyazlatıcı diş macunlarının sodium bikarbonat içerenlere göre rezin bazlı kompozitlerde daha az aşındırma yaptığı bildirilmiştir Bunun nedeni olarak da kalsiyum fosfatın daha az aşındırıcılığa ve iç sertliğine sahip olup çözünebilirliğinin fazla olması gösterilmiştir. ${ }^{8}$

Fırçalama sonrası hibrid kompozitlerin yüzeyinde meydana gelen pürüzlülüğün mikrofil ve nano kompozitlere göre daha fazla bulunduğu bildirilmiştir. ${ }^{33,34}$ Çalışmamızda BPW ile fırçalanan hibrid kompozitin pürüzlülüğünde istatistiksel olarak artma olmuştur ve en yüksek pürüzlülük değerine ulaşmıştır.

Suzuki ve ark., ${ }^{35}$ nanofil ve nanohibrid kompozitlerin kalsiyum karbonat karışımı ile fırçalama sonrası aşınmaları inceledikleri çalışmalarında; kompozitlerin yüzey morfolojilerinde anlamlı dercede aşınma ve değişme olduğunu tespit etmişlerdir. Grandio kompozitin yüksek aşınma direncine sahip olduğu ve fırçalama sonrası pürüzlülüğün diğer kompozitlere gore az olduğu görülmüştür.

Takahashi ve ark. ${ }^{36}$ iki nanohibrid, iki mikrohibrid ve bir ormacer kompozitin fırçalama sonrası yüzey özelliklerini incelediklerinde; Clearfil AP-X nanohibrid kompozit haricinde diğer kompozitlerin yüzeylerinde fırçalama sonrası pürüzlülükte anlamlı artış ve parlaklıkta azalış tespit etmişlerdir.

Dental materyaller üzerinde pürüzlülüklerine olan etkilerini değerlendirebilmek amacıyla farklı abrazivler ve beyazlatıcı ajanlar intiva eden farklı beyazlatıcı diş macunları kullanılmıştır. ${ }^{37}$ Diş fırçalama daha yumuşak olan polimer matriksi aşındırıp doldurucu partikülleri bırakarak pürüzlendirici etki ile sonuçlanabilir. ${ }^{38}$ Fırçalama etkisine ek olarak beyazlatıcı diş macunları yüzeydeki kalıntıları fiziksel olarak abrazivlerin yardımıyla ya da kimyasal olarak da peroksitler ile kaldırabilir. ${ }^{39}$

Sertlik materyalin en önemli fiziksel özelliklerinden kabul edilmektedir. Sertlikteki değişimler materyalin sertleşme reaksiyonlarının devam eden aşamalarını etkiler veya restoratif materyalin ömrünü etkiler. ${ }^{40,41}$

Yeşilyurt ve ark., ${ }^{42}$ yaptığı kompozitlerin mikro sertlik değerlerini inceledikleri çalışmada LED (Light emitting diode)' lerin kullanıldığı örneklerin mikro sertlik değerlerini QTH (Quartz tungsten halogen) cihazlardan anlamlı derecede yüksek bulduklarını bildirmişlerdir. Çalışmamızda kompozit rezinleri polimerize etmek için LED cihazı kullanılmıştır.

Şeffaf bant altındaki kompozit yüzeyi, yoğun rezin matriks tabakası olması nedeni ile en pürüzsüz yüzey olarak çalışmalarda yer alır. Bu rezinden zengin tabakaya bağlı olarak rezinlerin yüzey sertliğinin azaldığını gösteren çalışmalar mevcuttur. ${ }^{43}$

Şeffaf bant ile bitirilen rezin kompozitlerin mikrosertlik değerlerinin rezinin kendi sertlik değerlerinin altında olduğu bildirilmiştir. ${ }^{44}$ Şeffaf matriks ile bitirilen yüzeyler rezinden zengin tabaka dolaysı ile cila yapılan yüzeylerden daha pürüzsüz olabilir ancak, bu tabaka nedeniyle renklenmesi daha fazla olmaktadır. ${ }^{45}$

Rezin kompozitlerin yüzey kalitesini etkileyen en önemli faktörlerden biri de bitim ve polisajdır. Esnek alüminyum oksit diskler cila patları ile birlikte kullanıldığında elmas bitirme frezleri, tungsten karbid frezler, taş frez ve lastik frezlere göre daha düz yüzeyler oluştururlar. ${ }^{46,47}$

Çalışmamızda Vickers mikro sertlik ölçümleri yapılacağı için bu yumuşak tabakanın kaldırıması gereklidir. Rezinden zengin tabakayı kaldırmak için çalışmamızda literatürde belirtildiği üzere kompozit rezinlerin yüzeyi sıkça kullanılan, yapılan çalışmalarda en az yüzey pürüzlülüğü elde edildiği bildirilen Sof-Lex cila diskleri ile cilalanmıştır. 29,46-49 Tüm örnekler SoftLex cila disklerinin orta, ince ve süper ince diskleri ile 
firmanın talimatları doğrultusunda cilalanarak kompozit örneklerin üzerindeki bu rezinden zengin tabaka uzaklaştırılmıştır.

Örnekler oda sıcaklığında distile suda saklanmıştır. ${ }^{41}$ Sertlik ölçümünde materyallere fazla yük uygulandığında örnek yüzeylerinde çatlamalar oluştuğu bildirilmiştir. ${ }^{49,50}$ Çalışmamızda çatlak oluşumuna neden olamamak için 100 gr yük altında fırçalama yapılmıştır.

Çalışmamızda diş fırçası ile fırçalama sonrası hiçbir grupta mikro sertlik değerlerinde anlamlı değişme olmamıştır. BPW diş macunu ile fırçalanan BA kompozitin ortalama sertlikleri anlamlı derecede artmıştır. FS ve nano gruplarında (KC ve VG) ortalama sertlik değerleri azalırken, istatitiksel olarak anlamlı bulunmamıştır. OWT diş macunu ile fırçalanmada nano Kompozitlerin ( $K C$ ve VG) sertiğinde anlamlı düşme gözlenirken, hibrit kompozitte (BA) anlamlı derecede artma gözlenmiştir. Diş macunları arasındaki farkların içeriklerinde belirtilmemiş olan diğer kimyasallarla da ilgili olduğu düşünülmektedir.

Takahashi ve ark., ${ }^{36}$ fırçalama sonrası kompozit yüzeylerini SEM ile inceledikleri çalışmalarında; tüm kompozit yüzeylerinde fırçalama öncesi düzgün bir yüzey gözlemlerken; fırçalama sonrası bazı düzensizlikler ve yüzeyde partikül yerdeğiştirmelerinin olduğnu tespit etmişlerdir.

Moares ve ark. ${ }^{34}$ packable, mikrohibrid, nanohibrid ve mikrofil kompozitlerin fırçalama sonrası yüzeylerini SEM altında incelediklerinde; packable ve mikrohibrit kompozitlerin yüzeyinde doldurucuların yer değiştirdiği ve abraze bir matriks görüntüsü verdiğini bildirmişlerdir. Nanohibrid kompozitin ise daha düzgün bir yüzeye sahip olduğu görülmüştür. Çalışmalarında kullandıkları nanohibrit ve mikrofil kompozitlerin benzer sonuçlar gösterdiği de bildirilmiştir.

Bizim çalışmamızda da nanohibrid kompozitlerin yüzeyi daha düzgün bulunurken, mikrohibrid ve nanohibrid kompozit yüzeylerinin hiçbirinde fırçalama sonrasında yüzey morfolojilerinde değişikliğe rastlanılmamıştır. Bu sonucu fırçalama süresinin ve kullanılan diş macunlarının aşındırıcı oranlarının düşük olmasına bağlamaktayız.

\section{SONUÇLAR}

- Mikrohibrid tipte kompozitlerde organik yapının metakrilat ya da siloran olması mikro sertlikteki ve yüzey pürüzlülüğündeki değiş̧imler açısından istatistiksel olarak anlamlı fark oluşturmamıştır. Aşınmalarda doldurucu boyutunun matriks yapı tipine göre daha etkin olduğu görülmüştür.

- Nano kompozitlerin yüzeylerin fırçalama sonrası pürüzlülük değerleri anlamlı derecede artmamıştır.

- Beyazlatıcı diş macunu ile 14 gün fırçalama sonrasında; FS ve nano grupların ortalama sertlik değerleri azalırken, istatitiksel olarak anlamlı bulunmamıştır.

- SEM incelemelerinde x750 büyütmede alınan mikrograflarda hibrit, nanohibrit, nanofil ve siloran kompozitlerde rezin-matriks yapı arasında bozunma, çatlak ya da doldurucu kopmasına rastlanmamıştır.

- Nano yapı içeren kompozitlerin fırçalama sonrası yüzey pürüzlülüğü ve sertliklerinin daha az etkilendiği görülmüştür, in vitro çalışmamızın sonuçlarına gore; nano kompozitlerin mikrohibrid yapıdaki kompozitlere göre tercih edilmesini önermekteyiz.

\section{KAYNAKLAR}

1. Hossain A, Okawa S, Miyakawa O. Effect of toothbrushing on titanium surface: an approach to understanding surface properties of brushed titanium. Dent Mater 2006; 22:346-52.

2. Abouelatta OB, AA Abdel-Samad and AA Sakrana. Wear and surface roughness of current veneered materials after toothbrush/ dentifrice abrasion. J. Mater. Process. Technol 2005, 168: 431-7.

3. Sharif N, MacDonald E, Hughes J, Newcombe RG, Addy $M$. The chemical stain removal properties of 'whitening' toothpaste products: studies in vitro. $\mathrm{Br}$ Dent J 2000; 10:620-4.

4. Worschech CC, Rodrigues JA, Martins LR, Ambrosano GM. Brushing effect of abrasive dentifrices during at-home bleaching with $10 \%$ carbamide peroxide on enamel surface roughness. J Contemp Dent Pract 2006; 15:25-34.

5. Amaral CM, Rodrigues JA, Erhardt MC, Araujo MW, Marchi GM, Heymann HO, Pimenta LA .Effect of whitening dentifrices on the superficial roughness of esthetic restorative materials. J Esthet Restor Dent 2006; 18:102-8. 
6. Maldupa I, Brinkmane A, Rendeniece I, Mihailova A. Evidence based toothpaste classification, according to certain characteristics of their chemical composition. Stomatologija. 2012;14:1222.

7. Joiner A Whitening toothpastes: a review of the literature. J Dent. 2010;38 Suppl 2:e17-24.

8. Camargo IM, Saiki M, Vasconcellos MB, Avila DM. (2001). Abrasiveness evaluation of silica and calcium carbonate used in the production of dentifrices. J Cosmet Sci 2001; 52:163-7.

9. Liljeborg A, Tellefsen G, Johannsen G. The use of a profilometer for both quantitative and qualitative measurements of toothpaste abrasivity. Int J Dent Hygiene 2010; 8:237-243.

10. Lewis R, Dwyer-Joyce RS, Pickles MJ. Interaction between toothbrushes and toothpaste abrasive particles in simulated tooth cleaning. Wear 2004; 257:368-76.

11. Heintze SD, Forjanic M, Ohmiti K, Rousson V. Surface deterioration of dental materials after simulated toothbrushing in relation to brushing time and load. Dent Mater 2010; 26:306-19.

12. Lea SC, Khan A, Patanwala HS, Landini G, Walmsley AD. The effects of load and toothpaste on powered toothbrush vibrations. J Dent 2007; 35:350-4.

13. Neme AL, Frazier KB, Roeder LB, Debner TL. Effect of prophylactic polishing protocols on the surface roughness of esthetic restorative materials. Oper Dent 2002; 27:50-8.

14. Bollen CM, Lambrechts P, Quirynen M.Comparison of surface roughness of oral hard materials to the threshold surface roughness for bacterial plaque retention: A review of the literature. Dent Mater 1997; 13:258-69.

15. Dabanoğlu A . Nano kompozitler. T.D.B. Dişhek Klin Derg 2004; 17:20-5.

16. Mitra SB, Wu D, Holmes BN. An application of nanotechnology in advanced dental materials. J Am Dent. Assoc 2003; 134:1382-90.

17. Terry DA. Applications of nanotechnology. Pract Proced Aesthet Dent 2004; 16: 220-2.

18. Ure D, Harris J. Nanotechnology in dentistry: reduction to practice. Dent Update 2003; 30:10-5.

19. Chen MH. Update on dental nanocomposites J Dent Res. 2010; 89:549-60.
20. Malhotra N, Kundabala $M$, Shashirashmi A. Strategies to overcome polymerization shrinkage-materials and techniques. A review. Dent. Update. 2010; 37:115-8

21. Buergers R, Schneider-Brachert W, Hahnel S, Rosentritt M, Handel G. Streptococcal adhesion to novel low-shrink silorane-based restorative. Dent Mater 2009; 25:269-75.

22. Duarte S Jr, Botta AC, Phark JH, Sadan A. Selected mechanical and physical properties and clinical application of a new low-shrinkage composite restoration. Quintessence Int 2009; 40:631-8.

23. Eick JD, Kotha SP, Chappelow CC, Kilway KV, Giese GJ, Glaros AG, Pinzino CS. Properties of siloranebased dental resins and composites containing a stress-reducing monomer. Dent Mater 2007; 23:1011-7.

24. Furuse AY, Gordon K, Rodrigues FP, Silikas N, Watts DC. Colour-stability and gloss retention of silorane and dimethacrylate composites with accelerated aging. J Dent 2008; 36:945-52.

25. Ilie N, Hickel R. Macro-, micro- and nanomechanical investigations on silorane and methacrylate-based composites. Dent Mater 2009; 25:810-9.

26. Teixeira EC, Thompson JL, Piascik JR, Thompson JY. In vitro toothbrush-dentifrice abrasion of two restorative composites. J Esthet Restor Dent 2005; 17:172-80.

27. Pamir T, Korkut ZO, Tezel H, Köse T, Özataş F. Aşındırıcılık Derceleri Farklı Beyazlatıclı Diş Macunlarının Kompozit Rezinlerin Yüzey Pürüzlülüğü Ve Mikrosertliğin Etkilerinin İncelenmesi. GÜ Diş Hek Fak Derg 2007; 24: 89-95.

28. Joniot S, Salomon JP, Dejou J, Grégoire G. Use of two surface analyzers to evaluate the surface roughness of four esthetic restorative materials after polishing. Oper Dent 2006; 31:39-46.

29. Joniot SB, Gregoire GL, Auther AM, Roques YM. Three-Dimensional optical profilometry analysis of surface states obtained after finishing sequences for three composite resins. Oper Dent 2000; 25:311-5.

30. Yazici AR, Müftü A, Kugel G. Three Dimensional Surface Profile Analysis of Different Types of Flowable Restorative Resins Following Different finishing Protocols. J Contemp Dent Pra 2007; 8:117. 
31. Liljeborg A, Tellefsen G, Johannsen G. The use of a profilometer for both quantitative and qualitative measurements of toothpaste abrasivity. Int J Dent Hygiene 2010; 8:237-43.

32. Sawase T, Wennerberg A, Hallgren C, Albrektsson T, Baba K. Chemical and Topographical Surface Analysis of Five Different Implant Abutments. Clin Oral Impl Res 2000; 11:44-50

33. Heintze SD, Forjanic M. Surface roughness of different dental materials before and after simulated toothbrushing in vitro. Oper Dent 2005; 30:617-26.

34. Moraes RR, Ribeiro Ddos S, Klumb MM, Brandt WC, Correr-Sobrinho L, Bueno M. In vitro toothbrushing abrasion of dental resin composites: packable, microhybrid, nanohybrid and microfilled materials. Braz Oral Res $2008 ; 22: 112-8$

35. Suzuki $T$, Kyoizumi $H$, Finger $W J$, Kanehira $M$, Endo T, Utterodt A, Hisamitsu H, Komatsu M. Resistance of nanofill and nanohybrid resin composites to toothbrush abrasion with calcium carbonate slurry. Dent Mater J 2009; 28:708-16.

36. Takahashi R, Jin J, Nikaido T, Tagami J, Hickel R, Kunzelmann $\mathrm{KH}$. Surface characterization of current composites after toothbrush abrasion. Dent Mater J 2013;32:75-82.

37. Stein PS, Sullivan J, Haubenreich JE, Osborne PB. (2005). Composite resin in medicine and dentistry. JLong Term Eff Med Implants 2005;15:641-54.

38. Neme AL, Frazier KB, Roeder LB, Debner TL. Effect of prophylactic polishing protocols on the surface roughness of esthetic restorative materials. Oper Dent 2002; 27:50-8.

39. Amaral CM, Rodrigues JA, Erhardt MC, Araujo MW, Marchi GM, Heymann HO, Pimenta LA. Effect of whitening dentifrices on the superficial roughness of esthetic restorative materials. J Esthet Restor Dent 2006; 18:102-8.

40. Okada K, Tosaki S, Hirota K, Hume WR. Surface hardness change of restorative filling materials stored in saliva. Dent Mater 2001;17: 34-9.

41. Sarı ME, Koyuturk $A E$, Çankaya S. Günlük tüketilen yiyecek ve içeceklerin mine ve dolgu materyallerinin yüzey sertliği ve pürüzlülüğüne etkisi. J Dent Fac Atatürk Uni 2010 ;20:153-61
42. Yeşilyurt C, Sevilmiş HH, Kulacaoğlu N, Bulucu B, Taşdemir T. Rezin kompozitlerin polimerizasyonunda LED ışık kaynaklarının etkinliğinin incelenmesi. E Ü Dişhek Fak Derg 2006; 27:25-30.

43. Anfe T, Caneppele TMF, Agra CM, Vieira GF. Microhardness assessment of different commercial brands of resin composites with different degrees of translucence. Braz Oral Res 2008; 22:358-63.

44. Okte Villalta P, García-Godoy F, Lu H, Powers JM. Surface hardness of resin composites after staining and bleaching. Oper Dent 2006; 31:623-8.

45. Park SH, Krejci I, Lutz F. Microhardness of resin composites polymerized by plasma arc or conventional visible light curing. Oper Dent 2002; 27:30-7.

46. Polydorou O, Hellwig E, Auschill TM. The effect of different bleaching agents on the surface texture of restorative materials. 2006; 31:473-80.

47. Uçtaşli MB, Bala O, Güllü $A$. Surface roughness of flowable and packable composite resin materials after finishing with abrasive discs. J Oral Rehabil 2004, 31:1197-202.

48. Polydorou O, Hellwig E, Auschill TM. The effect of at-home bleaching on microhardness of six esthetic restorative materials. J Am Dent Assoc 2007;138;978-84.

49. Polydorou O, Moenting JS, Hellwig E, Auschill TM. Effect of inoffice tooth bleaching on the microhardness of six dental esthetic restorative materials. Dent Mater 2007; 23:153-8.

50. Müjdeci A. Yeni ağartıcı ajanların (paint-on) çeşitli restoratif materyallerin yüzey sertlikleri üzerine etkileri. A Ü Diş Hek Fak Derg 2005 ; 32 : 9-17.

\section{Yazışma Adresi:}

Dr. PInar Yilmaz ATALI

Marmara Üniversitesi

Dişhekimliği Fakültesi

Restoratif Diş Tedavisi Anabilim Dalı, Nişantaşı, İstanbul, Türkiye

Büyük Çiftlik Sokak No:6 Nisantasi

34365 Istanbul, Türkiye

Tlf +90 5325548964 e-posta:

faks: +902122465247

e-mail: pinar.atali@marmara.edu.tr 